\title{
Dr. Ira Greifer
}

\author{
Frederick Kaskel • Isidro B. Salusky
}

Received: 29 September 2014 / Revised: 1 October 2014 / Accepted: 2 October 2014 / Published online: 27 January 2015

(C) IPNA 2015

The Pediatric Nephrology community has lost a unique advocate and compelling voice for children with the passing of Ira Greifer, MD, Professor Emeritus at the Albert Einstein College of Medicine. Dr. Greifer passed away on September 17, 2014, in New York City. His early career was mentored by Dr. Henry Barnett, the first Chair of Pediatrics at the Einstein College of Medicine at a time when the field of pediatric nephrology was being defined at that institution by Dr. Barnett in collaboration with Chester Edelmann, Jr, and Adrian Spitzer.

Dr. Greifer' s extensive contributions to our subspecialty encompass legislation on and the delivery of health care, advocacy on behalf of children's needs, support of research and education in pediatrics and the subspecialty of nephrology, and advancing an international effort in pediatric health care via the International Pediatric Nephrology Association (IPNA).

Dr. Greifer first came to Albert Einstein College of Medicine 60 years ago and was the former Director of Pediatrics at the College Hospital where in the mid1960s he began developing a number of "firsts" in the country for both patients and families, including the following innovations:

- A family-centered care program called Mothering in the Hospital Program, which permitted parents to sleep at

F. Kaskel $(\bowtie)$

Department of Pediatrics, Montefiore Medical Center, 111 East 210th

St, Bronx, NY 10467, USA

e-mail: fkaskel@aecom.yu.edu

I. B. Salusky

UCLA School of Medicine, Los Angeles, CA, USA their child's bedside during hospitalization and also included the first ambulatory surgery program in the state of New York

- The only mainstreaming summer camp program for children on hemodialysis in partnership with the Frost Valley YMCA and the Eva Gottscho Foundation, which has served over 1,000 children with special needs

- A leadership role in the passage of national legislation entitling patients with kidney failure to receive dialysis and transplantation, and a vital collaboration with the then-Senator Jacob Javits fostering kidney research, including the establishment of the Kidney Disease Institute of New York State

Dr. Greifer was the former Medical Director of the National Kidney Foundation and President of the Kidney and Urology Foundation of America, and served on many scientific councils. Through his vision he has made possible the funding of training fellowships in nephrology, nutrition, social work, and nursing that to date have supported over 1,000 recipients. He also was one of the founders of IPNA and served as its Secretary General.

Dr. Greifer played a critical role in the expansion of the subspecialty worldwide. In recognition of his continued work with IPNA, Ira served as the Honorary President of the Scientific Congress in New York in 2010. The current IPNA training and educational Programs represent his legacy.

Ira Greifer's vision, leadership, and commitment to pediatrics and nephrology are appreciated around the world. He was one of the fathers of Pediatric Nephrology whose leadership and knowledge have 
improved the lives of countless children with kidney disease worldwide. His legacy is unparalleled and will inspire generations of practitioners and scientists to come.

He is survived by his beloved wife Carol, daughters Shelly Greifer, Lori Greifer Kaufman and son-in-law Glenn Kaufman, and daughter Julie and son-in-law Michael Swidler. He was the cherished grandfather of Hannah and Benjamin Kaufman and Hallie, Nora and Sam Swidler and dear brother of the late Naomi Weiss and David Greifer. He is also survived by family members Edward Sachs, Merle Greifer, Dedee and Stephen Lovell and many beloved nieces and nephews. Finally, the family of pediatric nephrology mourns this loss but will shine in his remembrance.

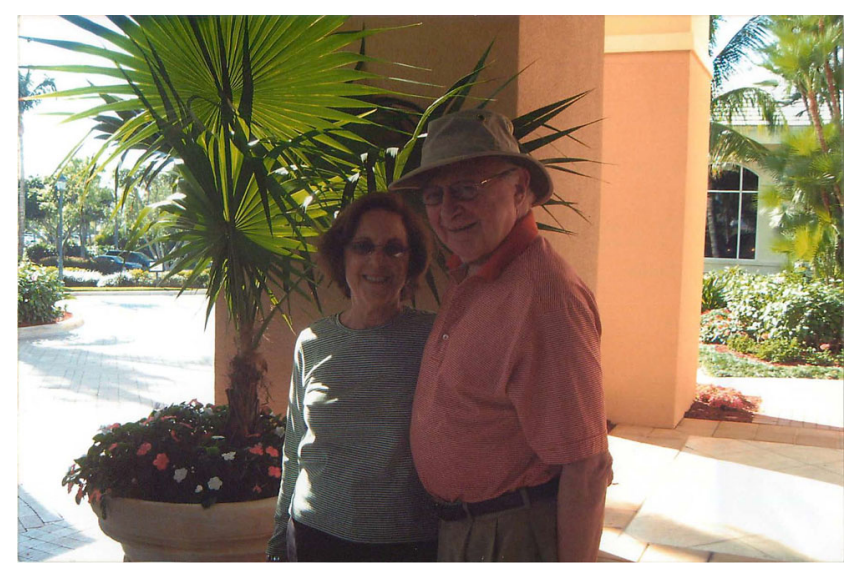

